\title{
AHS and CASI Processing for the REFLEX Remote Sensing Campaign: Methods and Results
}

\author{
Eduardo de MIGUEL, Marcos JIMÉNEZ, Irene PÉREZ, \\ Óscar G. de la CÁMARA, Félix MUÑOZ, \\ and José A. GÓMEZ-SÁNCHEZ \\ Instituto Nacional Técnica Aeroespacial (INTA), \\ Torrejón de Ardoz, Spain; e-mail: demiguel@inta.es
}

\begin{abstract}
The airborne spectroradiometers AHS and CASI were used as a source of hyperspectral and thermal remote sensing data during the REFLEX campaign. Data geolocation and a first simple atmospheric correction was performed by INTA in near-real time with a specific on-site setup and distributed to all campaign participants. In this paper we present briefly the AHS and CASI REFLEX flight campaign followed by a detailed description of the methodology used for image processing and finally the results obtained in terms of image quality. As a conclusion, near-real time processing for AHS and CASI level 1 geolocated products was successful as most of CASI level 2 results but further work is needed for achieving accurate AHS level 2 products.
\end{abstract}

Key words: AHS, CASI, image processing, remote sensing.

\section{INTRODUCTION}

The reflectance spectrum of a surface contains information on its composition and status; further information can be retrieved from its temperature.

Ownership: Institute of Geophysics, Polish Academy of Sciences;

(C) 2015 de Miguel et al. This is an open access article distributed under the Creative Commons Attribution-NonCommercial-NoDerivs license,

http://creativecommons.org/licenses/by-nc-nd/3.0/. 
The capability to retrieve the reflectance spectrum, the surface temperature or both is the basis of remote sensing techniques.

Hyperspectral remote sensing (Ben-Dor et al. 2013) is a powerful technology that produces a continuous record of the ground leaving radiance over a specific area in enough spectral bands as to recover the reflectance spectrum with a spectral resolution suitable for many bio-geophysical studies. On the other hand, thermal remote sensing (Prakash 2000) is aimed to measure extensively emitted radiance which in turn provides surface temperature and, eventually, the surface spectral emissivity.

Airborne sensors are currently the only way to obtain simultaneously the high spectral resolution required by hyperspectral remote sensing with a spatial resolution of few meters. The same applies for thermal remote sensing. In addition, airborne instrumentation provides a unique flexibility which is critical in research activities when coupling with extensive ground measurements or specific acquisition details (time of flight, sensor configuration or others) are needed.

AHS and CASI are two airborne spectroradiometers owned and operated by INTA (Spanish National Institute for Aerospace Technology). Together with calibration and navigation equipment, ground truth instrumentation, and a specific Processing and Archiving Facility (PAF) they form the INTA airborne remote sensing system. INTA offers this system as a technological service to public institutions or commercial companies. This is the system that was used as main source of remote sensing data during the REFLEX course.

The main objective of the REFLEX training course held in July 2012 in Las Tiesas experimental farm (Barrax, Spain) was to teach early-stage researchers how to organize and conduct an airborne field campaign with hyperspectral imaging sensors supporting their research in the framework of multi-scale ("leaf to ecosystem") land-atmosphere exchanges. An airborne campaign funded by EUFAR with the INTA C-212-200 RS aircraft in a well recognized ground reference agricultural site was part of the training course. More details on REFLEX are given in Timmermans et al. (2014).

The magnitude measured by airborne radiometers like AHS and CASI is just the incoming radiance at the sensor aperture. The magnitudes of interest in bio-geophysical studies, like surface reflectance, temperature and emissivity and their accurate and precise geolocation must be estimated from the original measurement through a set of data analysis procedures which is often labelled image processing (or, sometimes, pre-processing).

In this paper we present briefly the AHS and CASI REFLEX flight campaign followed by a detailed description of the methodology used for image processing and finally the results obtained in terms of image quality. 


\section{AHS AND CASI CHARACTERISTICS}

\subsection{AHS}

The INTA Airborne Hyperspectral Scanner (AHS) is an 80-bands airborne imaging radiometer developed by ArgonST (USA) and operated by INTA since 2003. Together with calibration and navigation equipment, auxiliary ground instrumentation. and a specific processing and archiving facility it forms the INTA AHS system.

The AHS has 63 bands in the reflective part of the electromagnetic spectrum, 7 bands in the 3 to 5 microns range and 10 bands in the 8 to 13 microns region. The first element of the optical subsystem is a rotating mirror which directs the surface radiation to a cassegrain-type telescope. The telescope design includes a so-called pfund assembly defining a $2.5 \mathrm{mrad}$ instantaneous field of view (IFOV) acting as a field stop for all bands and redirects the radiation to a spectrometer placed above the telescope. In the spectrometer dichroic filters split the incoming radiation in five optical ports: Port 1 (corresponding to VNIR wavelengths), Port 2a (for a single band at 1.6 micrometers), Port 2 (SWIR), Port 3 (MIR), and Port 4 (TIR). For each of these ports, a grating disperses the radiation and a secondary optical assembly focuses it onto an array of detectors which defines the spectral bands. Bands 22 to 24 and 60 to 63 are located at wavelengths with strong atmospheric absorption and have very low signal to noise ratio (SNR).

The AHS has two blackbodies (with size > IFOV) that are observed, respectively, at the start and end of each scanline. These blackbodies (BB1 and BB2) are thermally controlled and monitored; they have an emissivity above 0.95 in the MIR and TIR regions and a reflectivity $<1 \%$ in the VNIR-SWIR range. Therefore for each AHS band and image line, two "dark" or thermal reference pixels are available.

\subsection{CASI}

The CASI-1500i (abbreviated to CASI through this article) is a pushbroom imaging spectrometer based on a bidimensional CCD; the instrument measures the incoming radiance along up to 1500 spatial pixels "across-track" in up to 288 separate spectral bands covering a spectral range between 380 and $1050 \mathrm{~nm}$. The band-to-band distance between spectral rows is $2.4 \mathrm{~nm}$ while the bandwidth of each spectral row is around $3 \mathrm{~nm}$. Each (\#spatial $\times \#$ spectral) array of pixels is called a frame. FOV is $40^{\circ}$ and IFOV is $0.5 \mathrm{mrad}$, thus providing an across-track spatial resolution 5 times better than the INTA AHS at the same flight altitude.

Two different configurations of the CCD were used in REFLEX. In the spectral row sum 2 configuration (filename identification E2) 1440 out of the 1500 pixels across-track are recorded and a binning factor 2 is used to read the spectral information, resulting in 144 spectral bands with $\approx 5 \mathrm{~nm}$ band to 
Table 1

Flights performed and images acquired

\begin{tabular}{|c|c|c|c|c|c|}
\hline Flight & Survey & Line ID & Time (UTC) & Sensor & Image ID \\
\hline \multirow{8}{*}{$\begin{array}{c}25 \text { July } \\
(120725) \\
\text { diurnal } \\
\text { D01 }\end{array}$} & \multirow{2}{*}{$\begin{array}{c}\mathrm{D} 01-1 \\
Z \approx 1000 \mathrm{~m} \\
(\text { above terrain) }\end{array}$} & AHS + CASI P11 & $8: 43$ & $\begin{array}{l}\text { AHS } \\
\text { CASI }\end{array}$ & $\begin{array}{l}\text { P11BD } \\
\text { P11SF }\end{array}$ \\
\hline & & AHS + CASI P01 & $8: 51$ & $\begin{array}{l}\text { AHS } \\
\text { CASI }\end{array}$ & $\begin{array}{l}\text { P01BD } \\
\text { P01SF }\end{array}$ \\
\hline & \multirow{6}{*}{$\begin{array}{c}\mathrm{D} 01-2 \\
Z \approx 2000 \mathrm{~m}\end{array}$} & AHS + CASI P01 & $9: 02$ & $\begin{array}{l}\text { AHS } \\
\text { CASI }\end{array}$ & $\begin{array}{l}\text { P01ID } \\
\text { P01E2 }\end{array}$ \\
\hline & & AHS + CASI P02 & $9: 11$ & $\begin{array}{l}\text { AHS } \\
\text { CASI }\end{array}$ & $\begin{array}{l}\text { P02ID } \\
\text { P02E2 }\end{array}$ \\
\hline & & AHS + CASI P03 & $9: 19$ & $\begin{array}{l}\text { AHS } \\
\text { CASI }\end{array}$ & $\begin{array}{l}\text { P03I1 } \\
\text { P03E2 }\end{array}$ \\
\hline & & $\begin{array}{c}\text { AHS + CASI P03 } \\
\text { (repet. of above) }\end{array}$ & $9: 28$ & $\begin{array}{l}\text { AHS } \\
\text { CASI }\end{array}$ & $\begin{array}{l}\text { P03I2 } \\
\text { PR3E2 }\end{array}$ \\
\hline & & AHS + CASI P21 & $9: 46$ & $\begin{array}{l}\text { AHS } \\
\text { CASI }\end{array}$ & $\begin{array}{l}\text { P21ID } \\
\text { P21E2 }\end{array}$ \\
\hline & & AHS + CASI P22 & $9: 38$ & $\begin{array}{l}\text { AHS } \\
\text { CASI }\end{array}$ & $\begin{array}{l}\text { P22ID } \\
\text { P22E2 }\end{array}$ \\
\hline \multirow{2}{*}{$\begin{array}{c}25 \text { July } \\
\text { (120725) } \\
\text { night } \\
\text { N01 }\end{array}$} & $\begin{array}{c}\mathrm{N} 01-1 \\
Z \approx 1000 \mathrm{~m}\end{array}$ & $\begin{array}{l}\text { AHS P11 } \\
\text { AHS P11 } \\
\text { AHS P01 }\end{array}$ & $\begin{array}{l}21: 32 \\
22: 01 \\
22: 10\end{array}$ & $\begin{array}{l}\text { AHS } \\
\text { AHS } \\
\text { AHS }\end{array}$ & $\begin{array}{l}\text { P11B2 } \\
\text { P11B3 } \\
\text { P01B2 }\end{array}$ \\
\hline & $\begin{array}{c}\mathrm{N} 01-2 \\
Z \approx 2000 \mathrm{~m}\end{array}$ & $\begin{array}{l}\text { AHS P01 } \\
\text { AHS P21 } \\
\text { AHS P22 }\end{array}$ & $\begin{array}{l}22: 20 \\
22: 32 \\
22: 40 \\
\end{array}$ & $\begin{array}{l}\text { AHS } \\
\text { AHS } \\
\text { AHS }\end{array}$ & $\begin{array}{l}\text { P01I2 } \\
\text { P21I2 } \\
\text { P22I2 } \\
\end{array}$ \\
\hline \multirow{6}{*}{$\begin{array}{c}\text { 26 July } \\
\text { (120726) } \\
\text { diurnal } \\
\text { D02 }\end{array}$} & \multirow{2}{*}{$\begin{array}{c}\mathrm{D} 02-1 \\
Z \approx 2000 \mathrm{~m}\end{array}$} & P11 & $8: 42$ & $\begin{array}{l}\text { AHS } \\
\text { CASI }\end{array}$ & $\begin{array}{l}\text { P11BD } \\
\text { P11SF }\end{array}$ \\
\hline & & P01 & $8: 51$ & $\begin{array}{l}\text { AHS } \\
\text { CASI }\end{array}$ & $\begin{array}{l}\text { P01BD } \\
\text { P01SF }\end{array}$ \\
\hline & \multirow{3}{*}{$\begin{array}{c}\mathrm{D} 02-2 \\
Z \approx 2000 \mathrm{~m}\end{array}$} & P01 & $9: 07$ & $\begin{array}{l}\text { AHS } \\
\text { CASI }\end{array}$ & $\begin{array}{l}\text { P01ID } \\
\text { P01E2 }\end{array}$ \\
\hline & & $\mathrm{P} 21$ & $9: 17$ & $\begin{array}{l}\text { AHS } \\
\text { CASI }\end{array}$ & $\begin{array}{l}\text { P21ID } \\
\text { P21E2 }\end{array}$ \\
\hline & & $\mathrm{P} 22$ & $9: 25$ & $\begin{array}{l}\text { AHS } \\
\text { CASI }\end{array}$ & $\begin{array}{l}\text { P22ID } \\
\text { P22E2 }\end{array}$ \\
\hline & $\begin{array}{c}\mathrm{D} 02-1 \\
Z \approx 2000 \mathrm{~m}\end{array}$ & P01 & $9: 38$ & $\begin{array}{l}\text { AHS } \\
\text { CASI }\end{array}$ & $\begin{array}{l}\text { P01BD } \\
\text { P01E2 }\end{array}$ \\
\hline
\end{tabular}


band separation. In the alternative spatial mode (filename identification SF) all 1500 spatial pixels and 288 spectral bands are acquired with the cost of an increase in integration time and, therefore, along-track pixel size.

Raw images have a data depth of 14 bits. The so-called dark frames and uniformity frames are recorded before and after each imaged scene by the use of specific elements of a wheel mounted in front of the aperture. Dark frames are obtained by placing a shutter instead of the nominal slit while uniformity frames (intended to detect an eventual contamination of the aperture slit) use an optical diffuser. Masked columns in the edges of the CCD are used to estimate electronic offset while columns which are neither masked nor illuminated by the slit are used to estimate focal plane straylight.

\subsection{Flight campaign}

The flight campaign was designed after detailed discussions with the campaign participants. It considered, as main drivers, the need to have day and night time measurements and multiangle observations of key field areas and the repetition of some flight lines at two different altitudes in order to optimize, respectively, AHS and CASI configurations and pixel size. Note that as terrain is flat through the study area the observation zenith angle for each target is directly determined by its location within the sensor field of view.

The resulting design consisted of 12 flight lines that were performed on 25 July morning and early night; 6 of the flight lines were repeated on $26 \mathrm{Ju}-$ ly. Table 1 lists the flights performed and the images acquired.

Simultaneously to the flights the INTA team acquired reflectance spectra over several large, homogeneous targets suitable for ground reference after atmospheric correction. A CIMEL sunphotometer (CIMEL electronique, France) was operated on 25 and 26 July mornings to retrieve atmospheric water vapor and aerosol optical thickness at $550 \mathrm{~nm}$ for image atmospheric correction. Table 2 summarizes the values obtained for 25 July.

Table 2

CIMEL measurements of atmospheric water vapour,

Aerosol Optical Thickness (AOT) at $550 \mathrm{~nm}$ during the D01 flight session

\begin{tabular}{|c|c|c|c|}
\hline Time (UTC) & Sun zenith angle & $W V[\mathrm{~cm}]$ & AOT 550 $\mathrm{nm}$ \\
\hline $08: 40: 00$ & 49.753 & 2.080 & 0.248 \\
$08: 50: 00$ & 47.842 & 2.111 & 0.254 \\
$09: 00: 00$ & 45.940 & 2.147 & 0.262 \\
$09: 15: 00$ & 43.111 & 2.194 & 0.280 \\
$09: 30: 00$ & 40.318 & 2.177 & 0.284 \\
$09: 45: 00$ & 37.576 & 2.158 & 0.372 \\
10:00:00 & 34.899 & 2.147 & 0.323 \\
$10: 15: 00$ & 32.304 & 2.114 & 0.328 \\
10:30:00 & 29.827 & 2.059 & 0.327 \\
\hline
\end{tabular}




\section{IMAGE PROCESSING}

Image processing was performed on near-real time with a specific hardware and software setup deployed at the REFLEX course headquarters. Image processing consisted mainly of:

$\checkmark$ radiometric calibration and noise estimation,

- fine tuning of CASI spectral calibration,

a atmospheric correction and estimation of surface reflectance,

$\checkmark$ estimation of surface temperature and emissivity from AHS images,

$\checkmark$ geolocation and image orthorectification.

The description of the methods used is given below.

\subsection{AHS}

Radiometric calibration transforms the image values from digital number to at-sensor radiance $(L s)$. For VNIR/SWIR region:

$$
L s_{i, j, k}=c c_{k} / g_{k}\left(D N_{i, j, k}-D N b b_{i, k}\right) .
$$

The subscripts $\{i, j, k\}$ correspond to image \{row, column, band\}, respectively; $c c$ is the calibration coefficient, $g$ an adjustable electronic gain, $D N$ the raw Digital Number, and $D N b b$ the average of BB1 and BB2 data over a 15-rows moving window centered in row "i". Note that in this linear model the slope depends on laboratory measurements but the offset is estimated from the actual image. An empirical correction factor to $c c\left(f e_{k}\right)$ was introduced to account for system degradation since laboratory calibration. Actual values of $c c_{k}, g_{k}$, and $f e_{k}$ are reported in the REFLEX campaign metadata.

For MIR and TIR bands calibration is performed building $D N$-radiance model from the cold and hot blackbodies information (temperature, emissivity, and digital number). In this linear model both the slope and the offset are estimated from the actual image.

During image calibration the short-term standard deviation of BB1 and $\mathrm{BB} 2$ is computed and used as an estimation of the AHS instrumental noise.

Spectral calibration was performed in April 2012 at INTA facilities. A monochromator was used to illuminate the AHS with steps of $0.1 \mathrm{~nm}$ and a bandwidth around $5 \mathrm{~nm}$. The relative instrument response at the different wavelengths was used to build a responsivity curve for each band. These curves are nearly Gaussian and bandcenter and full width half maximum (FWHM) are annotated as metadata while the detailed spectral responsivity curves are available upon request to REFLEX users. AHS spectral performance is very stable under flight conditions and no specific in-flight calibration was performed for REFLEX images. 
The geolocation of each AHS pixel was performed using the direct georeferencing code PARGE (Schläpfer and Richter 2002). The inputs required are the exterior orientation information provided by the Inertial Navigation System Applanix POSAV and processed with Applanix POSPAC, a digital elevation model (DEM) and a detailed sensor model (including misalignment angles from the AHS geometric calibration). The basic output of the process is an Input Geometry file (IGM) for each image. IGM image files report the UTM Easting and Northing values derived by the geolocation process for each original image pixel.

The ENVI routine Georeference from IGM was used to generate sample orthorectified images on a cartographic UTM grid from a subset of the AHS bands. The output grid pixel size was $3 \mathrm{~m}$ for low altitude flights and $5 \mathrm{~m}$ for the high altitude flights. These georectified images were delivered to the REFLEX course participants mainly as a quicklook to display the expected output of the orthorectification process. The users of the REFLEX AHS data are then expected to choose a resampling algorithm or UTM grid size to produce the complete orthorectified data cube from the delivered IGM with the geolocated quicklook as reference.

Atmospheric and illumination correction was performed with ATCOR4 (Richter and Schläpfer 2002) which is a LUT-based implementation of MODTRAN5 targeted for airborne remote sensing data. The values used for ATCOR 4 configuration are reported in Table 4 . The visibility and aerosol type were initially selected according to the values estimated with the CIMEL sunphotometer deployed by INTA during the flight. Next, the SPECTRA module in ATCOR4 was used to refine scene visibility parameter using field spectra acquired simultaneously on reference surfaces with an ASD-FS3 spectroradiometer (Analytical Spectral Devices, Boulder, CO, USA). The ATCOR4 maritime aerosol type was the best fit for the specific scattering properties of the rather hazy atmosphere during the flights. Note that following the definitions in Schaepman-Strub et al. (2006) the magnitude estimated by ATCOR4 for solar bands is the Hemispherical-Directional Reflectance Factor (HDRF) of the observed surface. To compute surface temperature from ATCOR4, band AHS75 was selected because it has the highest SNR. A constant emissivity of 0.9825 (suitable for water and vegetation but not for bare soils) was assumed and with this value the Planck law was inverted from the ATCOR4-estimated atmospherically corrected radiance. The retrieved surface temperature was in turn used to estimate emissivity in the other thermal bands. This approach to temperature and emissivity estimation is very simplistic and was only performed to obtain a first approximation to thermal analysis. It was expected that REFLEX users would work in this issue with more rigorous procedures and specific ancillary data. 


\subsection{CASI}

CASI radiometric calibration was performed using ITRES software "radcorr". "Radcorr" first removes some non-signal additive terms from the measured digital count and next calibrates the corrected digital counts to atsensor radiance using laboratory coefficients.

The additive terms are estimated from the raw data analysis, as:

$$
D N_{i, j, k}=D N 0_{i, j, k}-D C_{k}-I S L_{i, k}-F S S_{i, k},
$$

where the subscripts $\{i, j, k\}$ correspond again to image frow, column, band\}, respectively. $D N$ is the corrected but uncalibrated signal, $D N 0$ is the raw signal, $D C$ is the average dark data for band $k$ (including dark current and electronic offset) as measured just before image acquisition, ISL is the internally scattered light for band $k$, and FSS is frame shift smear. This is a non-target signal originated during the transfer of data from the scene image area of the CCD to its read-out register. It occurs mainly in the spectral dimension and is maximum at longer wavelengths. "Radcorr" includes an algorithm to estimate and remove frame shift smear.

Once the corrected $D N$ is available, the calibration is performed by

$$
L s(i, j, k)=1 / s c_{j, k} D N_{i, j, k},
$$

where $s c_{j, k}$ is the absolute calibration coefficient for band $k$ and detector $j$. It is computed in the laboratory, illuminating the system with a half meter integrating sphere from Sphere Optics (NH, USA). Dark frames are used to obtain the system output at zero input radiance. Considering also CCD smear and straylight, a linear model relating digital values to input radiance is built for each detector element. For this purpose we use the Itres software Sparcal. The radiometric calibration coefficients for REFLEX was performed at INTA in March 2012.

For noise estimation, the uniformity frames acquired right before each image file are used. These frames are collected with a semi-transparent diffusing cover between sensor and scene, and only retain the scene low frequency structure; they are, thus, a good candidate for instrumental noise assessment. After removal of the low frequency structure the standard deviation of the radiometrically calibrated uniformity data was taken as estimation of CASI instrumental noise and reported in the image metadata.

Pushbroom sensors are generally affected by spectral shift, i.e., a change in the effective band center of the detector during image acquisition when compared to the nominal (laboratory) band center. The Remote Sensing Area at INTA has developed a tool to create an image specific CCD spectral map that works on CASI modes SF, E2, similar to the one described in Guanter et al. (2006). The image specific CCD spectral map can then be input to 
"speccorr" which is an Itres tool to estimate the radiance levels in the nominal band centers (those reported to the user) given the actual band centers defined by our tool. Every REFLEX CASI image was analysed to assess its shift and was afterwards shifted to match the nominal bandwidths.

The geolocation was performed with the same basis than in AHS. However, for CASI the direct geolocation algorithm used is "geocor", a tool provided by Itres. The image geometry map is in this case identified with the acronym GLU (Geographic Look-up Table).

A relevant point in CASI is the choice of output pixel size on a cartographic UTM grid. To maximize the spectral information the selected integration time defines an along-track pixel size which is significantly above the across-track pixel size defined by the instrument IFOV (see Table 3). In such cases, resampling to a square grid must consider a compromise between redundancy (original samples that are used more than once when generating the resampled product) and data loss (raw original samples that are not mapped to the resampled product). The values used in the geolocated quicklook are reported in column 4 in Table 3.

Atmospheric correction to transform the $\mathrm{L} 1$ product (at sensor radiance) to L2 (HDRF) was performed with ATCOR4, configured as in Table 4.

Table 3

Actual ground IFOV (GIFOV) in across-track (X) and along-track (Y) directions versus the pixel size used in the georectified imagery

\begin{tabular}{|l|c|c|c|}
\hline \multicolumn{1}{|c|}{ Configuration } & GIFOV-X (nadir) & GIFOV-Y (nadir) & Output grid \\
\hline Row sum 2 (E2) & $1.4 \mathrm{~m}$ & $1.7 \mathrm{~m}$ & $1.25 \mathrm{~m}$ \\
Spatial (SF) & $0.9 \mathrm{~m}$ & $3.2 \mathrm{~m}$ & $1.50 \mathrm{~m}$ \\
\hline
\end{tabular}

Note: The GIFOV figures given are average values for nadir view for the two CASI configurations.

Table 4

Parameters used in the configuration of ATCOR4

\begin{tabular}{|l|c|c|c|c|c|}
\hline \multicolumn{1}{|c|}{ Flight } & \multicolumn{2}{c|}{ D01 } & N01 & \multicolumn{2}{c|}{ D02 } \\
\hline Sensor & AHS & CASI & AHS & AHS & CASI \\
\hline Aerosol model & maritime & maritime & not used & maritime & maritime \\
\hline Visibility $[\mathrm{km}]$ & 40 & 40 & not used & 30 & 30 \\
\hline Water vapor & variable & variable & $\begin{array}{c}\text { constant } \\
2.9 \mathrm{gr} / \mathrm{cm}^{2}\end{array}$ & variable & variable \\
\hline
\end{tabular}

Note: Visibility and aerosol type where selected using the field spectra as reference data for adjusting ATCOR4, but shall not be considered an estimation of the actual atmospheric conditions. 


\section{RESULTS}

All acquired images were successfully processed. A number of points relevant to image quality are reported below.

AHS bands 22, 23, and 64 are at the edge of atmospheric windows; they have very low signal to noise ratio and are unlikely to be useful. Bands 44 and 46 have a very low SNR due to detector malfunctions. They should be used with reservations. File AHS P11BD on 26 July shows a recording anomaly, namely a set of corrupted image rows (rows 4587 to 4600) followed by 20 rows with duplicated info and finally a small data gap.

In CASI images some samples from very low reflectance targets display a radiance $<0$ in the water absorption region around $935 \mathrm{~nm}$ and beyond $1020 \mathrm{~nm}$. This is due to the combination of low signal, noise, and an excess straylight correction which unfortunately could not be optimized.

A visual check of the geolocation performance is obtained overlaying two different images acquired over the same area but with different tracks or with different sensors as shown in Fig. 1. The smooth transition between images means a good relative registration.

The absolute geographical accuracy of the images is initially estimated considering the expected uncertainty of input data, as determined by the POSPAC quality tools and the misalignment information calculated by INTA during the geometric calibration. It is expected to be about half a pixel.

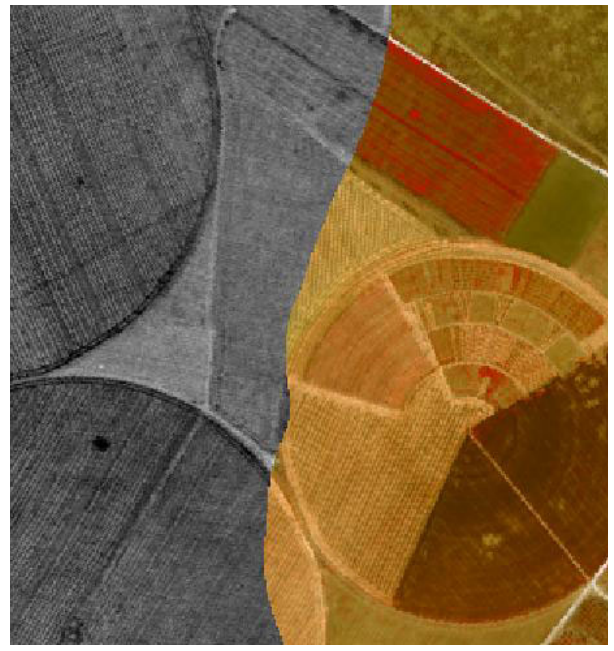

(a)

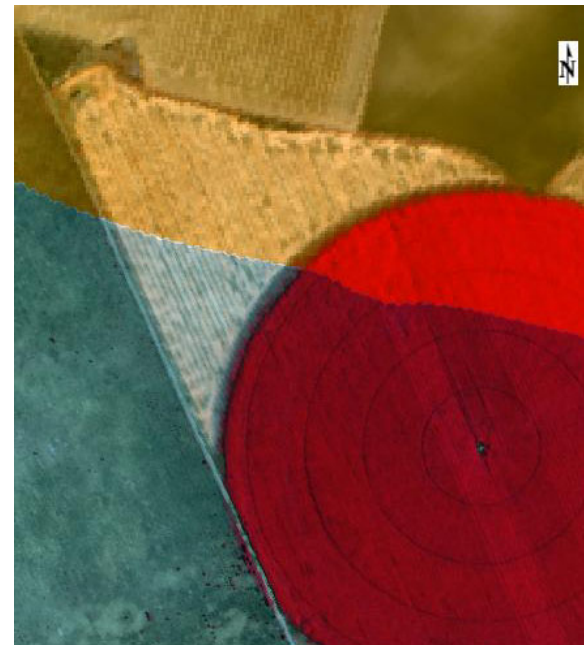

(b)

Fig. 1: (a) Part of a thermal AHS band from P11B3 (night flight, NE to SW track) overlaid on top of a color infrared composition of AHS P01BD (morning flight, NW to SE); (b) Detail of CASI color infrared from P01E2 overlaid on AHS P01BD; the apparent color difference is a result of specific enhancement for displaying purposes. 
This was confirmed by visual check against available orthoimagery and AHS to CASI comparison. For the REFLEX images no estimation of geolocation error from ground control points was considered necessary. Note that measurements of absolute accuracy on resampled, georectified images must account for the effects of the resampling which, as explained above, is a critical factor in CASI and could introduce more uncertainty than using the expected error budget.

The radiometric quality can be reported in terms of noise which determines the radiometric resolution and of absolute radiometric accuracy.

From the user's side it is more relevant to estimate the noise equivalent in terms of surface reflectance, temperature or emissivity, or in terms of SNR. Figure 2 shows AHS and CASI SNR for P01BD on 25 July and the AHS noise equivalent in temperature (NEdT) for the same image. For SNR signal is estimated as the average scene value while noise is computed from dark data as described in previous sections.

The AHS VNIR performance is excellent with SNR well beyond 500 . Most of the CASI bands show also a good SNR, above 100; but in the blue end and above $980 \mathrm{~nm}$ noise is significant. On the SWIR, AHS performance is not so good (apart from the problems in bands 44 and 46), and beyond 2.4 microns data analysis is difficult. Finally, AHS TIR data show a very low noise with amplitude below $0.25^{\circ} \mathrm{C}$, except in the longer wavelengths.

Another look to radiometric quality is given by the comparison of AHS and CASI measurements over the same area. An example is shown in Fig. 3.

For evaluating the absolute radiometric accuracy, the field spectra acquired with ASD-FS3 were used. Figure 4 shows a field spectrum obtained

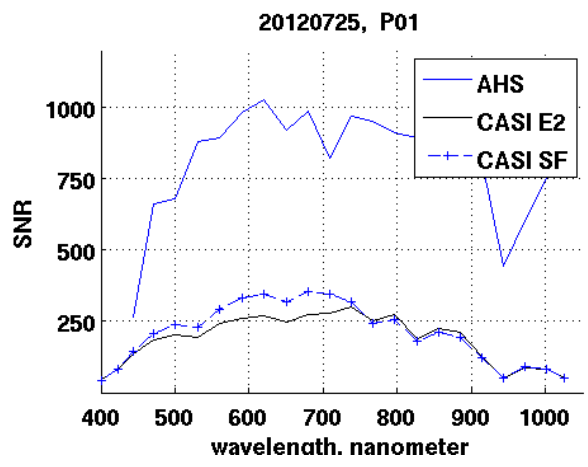

(a)
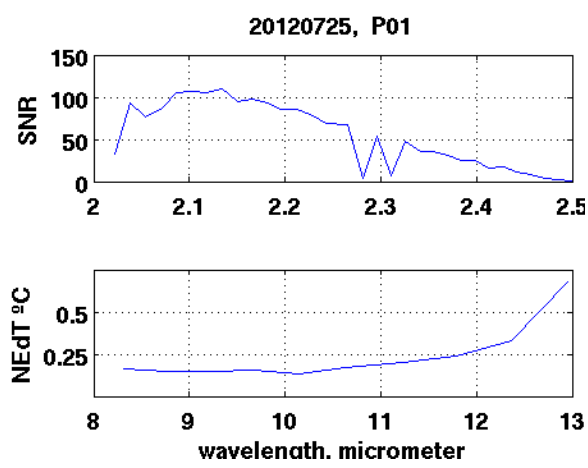

(b)

Fig. 2. Noise estimation for P01 scene: (a) SNR for AHS and CASI VNIR bands; note that CASI noise is reported for both E2 and SF images but only for a subset of bands corresponding to AHS bandcenters; (b) SNR for AHS SWIR bands and NEdT for TIR bands. 

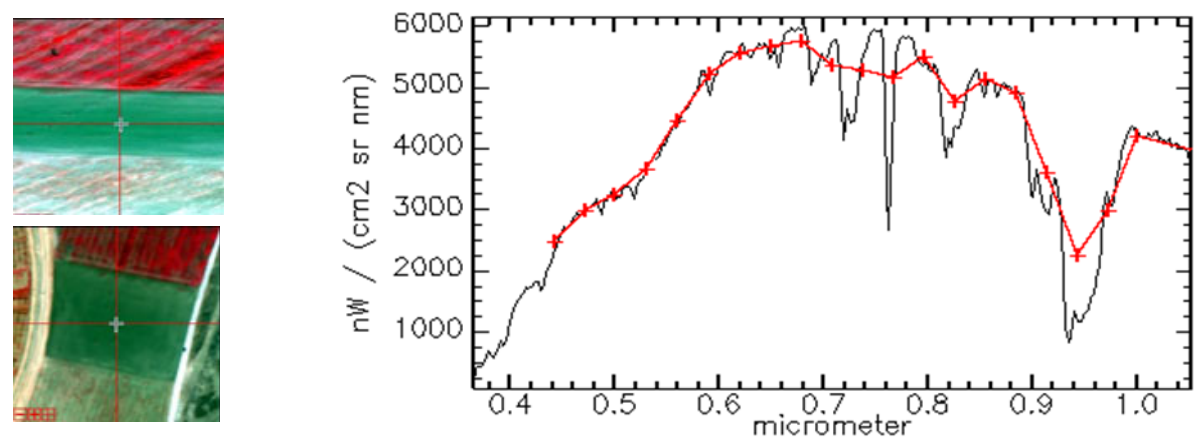

Fig. 3. Spectral radiance measured by AHS (red line, plus symbols) and CASI (black line) on the same bare soil location. The images used, displayed left to the plot, are AHS P01BD and CASI P01SF.
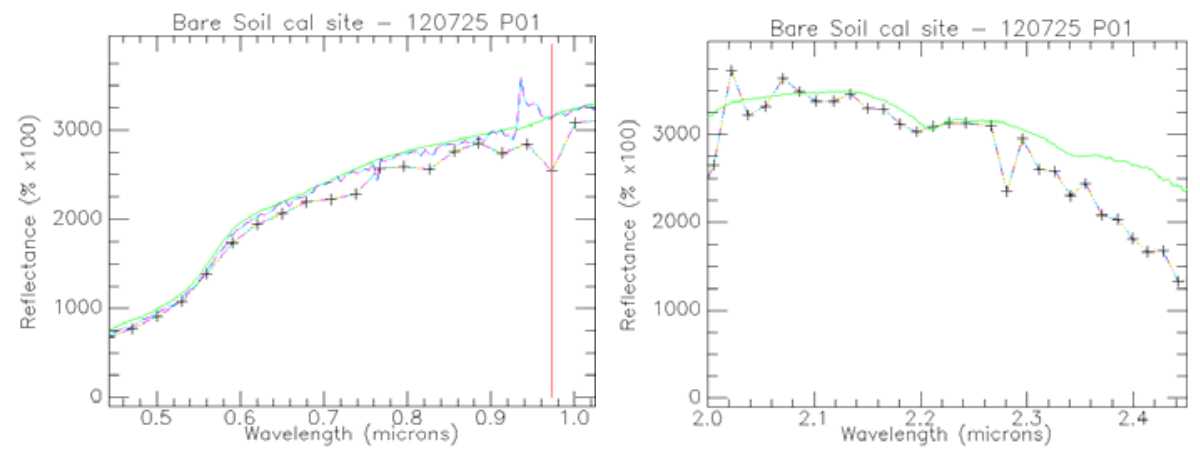

Fig. 4. Reflectance spectrum of the bare soil calibration site as estimated for CASI (blue dashed line), AHS (black plus line), and ASD-FS3 (green line).

from ASD-FS3 data on a bare soil surface. The spectra obtained from AHS and CASI are overlaid. The CASI data match accurately the ground truth, except for bands in the $935 \mathrm{~nm}$ water vapor absorption. For AHS the match depends on the band considered. Again, bands affected by water vapor absorption show the worst match. The signal underestimation around $1000 \mathrm{~nm}$ could be due to adjacency effects. These problems points out to the need of an improved atmospheric correction if such bands are relevant for the intended analysis. On the thermal side, the retrieved surface temperature was validated with simultaneous ground measurements from a water pond, showing a difference below $1^{\circ} \mathrm{C}$. It is assumed that this uncertainty is applicable to most images on water and vegetation where the 0.9825 emissivity is valid; but the simple temperature-emissivity separation applied does not support the rigorous use of the thermal information for other surfaces. 


\section{CONCLUSIONS}

The REFLEX flight campaign was performed successfully with all planned images acquired and processed. Radiometric correction and calibration of the data was successful and, in the case of CASI, also spectral recalibration. The geolocation of the images was achieved on-site with results that are similar to those obtained offline at the INTA facilities. Overall, the methods applied to obtain level 1 orthorectified images performed flawlessly in near real time, showing that it is possible to process AHS and CASI images in operational conditions outside the INTA facilities.

The quick and operational atmospheric correction performed on the data led to a first estimation of surface magnitudes. For CASI the obtained reflectance products are accurate enough for most users. But improved methods considering advanced algorithms and all available ancillary data and ground truth should be applied for detailed analysis of the AHS thermal data and water absorption bands. This shows that near real time estimation of level 2 AHS and (to a lesser extent) CASI products for operational bio-geophysical studies is still an open task.

Acknowledgments. The work described in this paper has received funding from the European Community's 7th Framework Programme (FP7/2008-2013) under EUFAR contract No. 227159, and Cost Action ES0903-EUROSPEC. The dedication and expertise of the INTA and G47 flight team were key factors for the success of the campaign.

\section{References}

Ben-Dor, E., D. Schläpfer, A.J. Plaza, and T. Malthus (2013), Hyperspectral remote sensing. In: M. Wendisch, and J.-L. Brenguier (eds.), Airborne Measurements for Environmental Research: Methods and Instruments, Wiley-VCH Verlag \& Co. KGaA, Weinheim, 413-456, DOI: 10.1002/9783527653218. ch8.

Guanter, L., R. Richter, and J. Moreno (2006), Spectral calibration of hyperspectral imagery using atmospheric absorption features, Appl. Optics 45, 10, 23602370, DOI: 10.1364/AO.45.002360.

Prakash, A. (2000), Thermal remote sensing: concepts, issues and applications, Int. Arch. Photogram. Remote Sens. 32, B1, 239-243.

Richter, R., and D. Schläpfer (2002), Geo-atmospheric processing of airborne imaging spectrometry data. Part 2: Atmospheric/topographic correction, Int. J. Remote Sens. 23, 13, 2631-2649, DOI: 10.1080/01431160110115834. 
Schaepman-Strub, G., M.E. Schaepman, T.H. Painter, S. Dangel, and J.V. Martonchik (2006), Reflectance quantities in optical remote sensing - definitions and case studies, Remote Sens. Environ. 103, 1, 27-42, DOI: 10.1016/ j.rse.2006.03.002.

Schläpfer, D., and R. Richter (2002), Geo-atmospheric processing of airborne imaging spectrometry data. Part 1: Parametric orthorectification, Int. J. Remote Sens. 23, 13, 2609-2630, DOI: 10.1080/01431160110115825.

Timmermans, W., C. van der Tol, J. Timmermans, M. Ucer, X. Chen, L. Alonso, J. Moreno, A. Carrara, R. Lopez, F. de la Cruz Tercero, H.L. Corcoles, E. de Miguel, J.A.G. Sanchez, I. Pérez, B. Franch, J.-C.J. Munoz, D. Skokovic, J. Sobrino, G. Soria, A. MacArthur, L. Vescovo, I. Reusen, A. Andreu, A. Burkart, C. Cilia, S. Contreras, C. Corbari, J.F. Calleja, R. Guzinski, C. Hellmann, I. Herrmann, G. Kerr, A.-L. Lazar, B. Leutner, G. Mendiguren, S. Nasilowska, H. Nieto, J. Pachego-Labrador, S. Pulanekar, R. Raj, A. Schikling, B. Siegmann, S. von Bueren, and Z.B. Su (2015), An overview of the Regional Experiments For Land-atmosphere Exchanges 2012 (REFLEX 2012) campaign, Acta Geophys. 63, 6, 1465-1484, DOI: 10.2478/s11600-014-0254-1 (this issue).

Received 28 January 2014 Received in revised form 5 November 2014 Accepted 5 January 2015 